\title{
Pulmonary-intestinal cross-talk in mucosal inflammatory disease
}

\author{
S Keely ${ }^{1}$, NJ Talley ${ }^{2}$ and PM Hansbro ${ }^{3}$
}

Chronic obstructive pulmonary disease (COPD) and inflammatory bowel diseases (IBDs) are chronic inflammatory diseases of mucosal tissues that affect the respiratory and gastrointestinal tracts, respectively. They share many similarities in epidemiological and clinical characteristics, as well as in inflammatory pathologies. Importantly, both conditions are accompanied by systemic comorbidities that are largely overlooked in both basic and clinical research. Therefore, consideration of these complications may maximize the efficacy of prevention and treatment approaches. Here, we examine both the intestinal involvement in COPD and the pulmonary manifestations of IBD. We also review the evidence for inflammatory organ cross-talk that may drive these associations, and discuss the current frontiers of research into these issues.

\section{INTRODUCTION}

Chronic obstructive pulmonary disease (COPD) and inflammatory bowel diseases (IBDs) are mucosal inflammatory diseases affecting the respiratory system and gastrointestinal tract, respectively. COPD affects 64 million people worldwide and is the fourth leading cause of death. ${ }^{1}$ IBD has a prevalence of $>300 / 100,000$ globally and there has been a dramatic increase in the incidence of IBD over the last 50 years. ${ }^{2,3}$ COPD and IBD are both chronic diseases, which are driven by recurrent cycles of inflammation that lead to tissue damage and remodeling, which progressively worsen symptoms. There are no cures for either disease and both require lifelong health maintenance, for which current therapies are suboptimal. ${ }^{4-6}$ Many of the similarities in the pathological features of COPD and IBD are a result of the common physiology of the respiratory and gastrointestinal systems.

\section{Common physiology of the respiratory and gastrointestinal tracts}

Structurally, the respiratory and gastrointestinal tracts have many similarities. ${ }^{7,8}$ Both have an extensive, highly vascularized, luminal surface area, ${ }^{9-12}$ which is protected by a selective epithelial barrier ${ }^{13-15}$ and an overlying mucus-gel layer ${ }^{16,17}$ from commensal bacteria, pathogens, and foreign antigens. These epithelial surfaces cover a submucosal layer of loose connective tissue and mucosa-associated lymphoid tissue, composed of resident lymphocytes. This lymphoid tissue regulates antigen sampling, lymphocyte trafficking, and mucosal host defense. ${ }^{18,19}$ Respiratory and gastrointestinal epithelia share a common embryonic origin in the primitive foregut, ${ }^{20,21}$ which may account for their similarities. However, it is most likely that it is the similar inflammatory and immune components of these organs that are the cause of the overlap in pathological changes in respiratory and intestinal mucosal diseases.

\section{Chronic obstructive pulmonary disease}

COPD is an umbrella term describing a group of conditions characterized by prolonged airflow obstruction and loss of the functional capacity of the lungs. Patients suffer from chronic bronchitis and emphysema that lead to breathing difficulties (dyspnea). ${ }^{22}$ Symptoms are induced by exaggerated and chronic inflammatory responses to the noxious insult of smoke exposure, with periodic exacerbations of disease typically caused by bacterial or viral infection..$^{23}$ Smoking is the major causal risk factor in COPD in westernized countries, but wood smoke and pollution are important in other areas, and there are genetic and epigenetic components. ${ }^{24}$ Recent studies have shown that exposure to respiratory infections or hyperoxia in early life may also contribute to the development of COPD. ${ }^{25,26}$

\footnotetext{
${ }^{1}$ School of Biomedical Sciences and Pharmacy and Hunter Medical Research Institute, The University of Newcastle, NSW, Australia. ${ }^{2}$ Faculty of Health and Hunter Medical Research Institute, The University of Newcastle, NSW, Australia. ${ }^{3}$ Centre for Asthma and Respiratory Disease, School of Biomedical Sciences and Pharmacy and Hunter Medical Research Institute, The University of Newcastle, NSW, Australia. Correspondence: S Keely and PM Hansbro (Simon.Keely@newcastle.edu.au and Philip.Hansbro@newcastle.edu.au) 


\section{Inflammatory bowel disease}

IBD is a term that describes a group of inflammatory diseases of the gastrointestinal tract. Ulcerative colitis (UC) and Crohn's disease (CD) are the two most common forms of IBD. ${ }^{27}$ Physiologically, UC and CD are quite distinct. UC is characterized by continuous, superficial ulceration of the colon, whereas CD manifests with transmural, sporadic (skip) lesions and may occur at any point along the digestive tract. ${ }^{28,29}$ Both conditions are associated with excessive daily bowel movements, severe abdominal pain, diarrhea, weight loss, malnutrition, and intestinal bleeding. The causes of IBD are unclear; however, several factors are known to contribute to the onset of the disease including genetic risk, environmental stress, the intestinal microbiome, and inflammatory dysfunction. ${ }^{30}$

\section{Inflammatory organ cross-talk in COPD and IBD}

It is widely accepted that secondary organ disease occurs in both COPD and IBD. ${ }^{31-37}$ There is much recent clinical interest in intestinal manifestations of COPD, and an increasing number of studies has highlighted the prevalence of pulmonary inflammation in IBD. At an epidemiological level, there is a strong association between the incidence of COPD and CD. ${ }^{38-40}$ A population-based cohort study performed by Ekbom et al., 39 showed that the risk of CD in COPD sufferers was 2.72 times higher than that in healthy controls and greater than the risk reported for smoking alone. There is also a familial risk factor, with an increased risk of CD among the first-degree blood relatives of COPD sufferers, although shared environmental factors may account for this. Specific intestinal manifestations of COPD include atrophic gastritis and nutritional absorption deficiency in the small intestine. ${ }^{34,41}$

Conversely, COPD has been shown to be a significant mortality factor among CD sufferers, ${ }^{38,40}$ with standardized mortality ratios of 2.5-3.5 for COPD in the CD population. Kuzela et al. ${ }^{42}$ demonstrated a high incidence of abnormal pulmonary function in both CD and UC patients, despite a lack of radiological abnormalities. Similar findings by Tzanakis et al. ${ }^{31,43,44}$ led them to propose that patients suffering from IBD should undergo pulmonary evaluation including physical examination, chest X-ray, and pulmonary function testing. Black et al. ${ }^{33}$ performed a literature survey that identified 55 articles citing thoracic disorders in IBD patients, with large airway involvement accounting for 39\% of these associations. Three more specific studies of randomly selected IBD patients showed incidence rates of pulmonary organ involvement at $44,{ }^{45} 48,{ }^{46}$ and $50 \% .{ }^{47}$ The symptoms manifested as interstitial lung disease, increased numbers of alveolar lymphocytes, and a reduction in the diffusion capacity of the lung. Pulmonary involvement was more likely in UC, but was still significant in CD.

Hence, there is a clear but undefined link between inflammatory diseases in the respiratory and intestinal systems. Although the associations have been clearly identified in the clinical literature, there have been few basic research studies that have investigated the mechanisms of the inflammatory cross-talk involved.

\section{COMMON RISK FACTORS IN COPD AND IBD}

Both COPD and IBD are multifactorial diseases and share many aspects of the classical "triad" of risk factors: environmental factors, genetic susceptibility, and microbial involvement. In addition, both conditions exhibit clear signs of immunological dysfunction in their pathologies. However, although smoke or particulate inhalation is a critical environmental factor for COPD, the corresponding factors for IBD are ill-defined. Conversely, although there is a clear link between the intestinal microbiome and IBD, the potential of an intrinsic lung microbiome as a risk factor in COPD has only recently emerged.

\section{Smoking as a risk factor for COPD and IBD}

Cigarette smoking is the single most important risk factor in COPD. Approximately $80 \%$ of people with COPD are past or present smokers. Toxins and particulate matter in inhaled smoke induce acute inflammation in the airways. With repeated insult, inflammation becomes chronic and damages the airway epithelium and lung tissue. ${ }^{4-50}$ Eventually this leads to remodeling of the respiratory epithelium, emphysema, and chronic disease. However, only between 15 and 50\% of all smokers develop COPD, indicating that smoke inhalation alone is not sufficient to induce disease $\mathrm{e}^{51,52}$ and that other risk factors are likely contribute to the development of COPD. Twin and familial studies have suggested the involvement of genetic factors, with firstdegree relatives of COPD sufferers at increased risk. ${ }^{53,54}$

Smoking is also a risk factor for IBD and significantly increases the risk of developing CD by threefold. ${ }^{55-59}$ In contrast, and surprisingly, the prevalence of UC among smokers is low, with smoking alleviating symptoms of disease. ${ }^{59,60}$ This is exemplified by familial studies of siblings who are genetically susceptible to IBD. In these studies, smokers were shown to be more likely to develop CD and non-smokers to develop UC. ${ }^{61}$ Nevertheless, ex-smokers seem to be at increased risk of UC than those who have never smoked. ${ }^{62-64}$

The issue is further complicated when incidences of smokers and IBD are correlated as a whole. Eastern countries tend to have a much higher smoking rate than do western countries; ${ }^{1}$ yet western countries have a higher incidence of $\mathrm{CD}$, but not UC, compared with eastern countries. ${ }^{65,66}$ The lack of epidemiological correlation between smoking and CD incidence in the east-west divide suggests that, like COPD, smoking by itself is not sufficient to induce IBD. Studies in animal models of CD-like colitis have demonstrated that smoke exposure exacerbates existing colitis in wild-type animals. ${ }^{67-69}$ This suggests that smoking can augment existing mucosal inflammation, although no consensus on mechanism has been achieved. Thus, although smoking has an obvious impact on both respiratory and gastrointestinal health, the nature of these phenomena is poorly understood.

\section{Genetic risk of COPD and IBD}

Both COPD and IBD have known genetic risk factors. To date, four genetic risk factors have been formally identified for COPD. Deficiency of $\alpha_{1}$ anti-trypsin (A1AT), an enzyme 
and a serum trypsin inhibitor that protects against protease remodeling in the airway, accounts for $2 \%$ of COPD in the population. ${ }^{70,71}$ Recently, genes for $\alpha$-nicotinic acetylcholine receptor (CHRNA3/5), ${ }^{72}$ hedgehog-interacting protein $(H H I P),{ }^{73,74}$ and iron-regulatory protein 2 (IREB2) ${ }^{75,76}$ have been shown to be potential susceptibility loci for COPD. However, functional end points have yet to be determined for how these genes influence the development of COPD.

Both CD and UC are known to have genetic risk factors, and both ethnic and familial associations have been shown. ${ }^{54,77,78}$ Mutations in genes for nucleotide-binding oligomerization domain containing 2 (NOD2), ${ }^{79-81}$ autophagy-related protein 16-1 (ATG16L1), ${ }^{82,83}$ interleukin-23 receptor (IL23R), ${ }^{84,85}$ and immunity-related guanosine- $5^{\prime}$-triphosphatase family M protein $\left(I R G M^{86}\right)$ have been shown to dramatically increase the risk of $\mathrm{CD}$. A recent study has also identified a NOD2 mutation in COPD populations offering a possible link between this condition and $\mathrm{CD} .{ }^{87}$ These genes code for proteins that control responses to infection at the intestinal mucosa and regulate autophagy. Thus, a paradigm has developed that a defect in bacterial clearance in $\mathrm{CD}$ may be one of the key triggers for disease onset. Polymorphisms of human leukocyte antigen class II genes also have a strong association with UC, suggesting that lymphocyte regulation is an important factor in its development. ${ }^{88,89}$ Recent studies have made substantial progress in understanding gene associations with UC. Among the new susceptibility loci identified are laminin subunit $\beta-1$ (LAMB1), ${ }^{90}$ extracellular matrix protein 1 (ECM1), ${ }^{91}$ hepatocyte nuclear factor 4- $\alpha$ (HNF4A), ${ }^{90}$ and cadherin-1 and cadherin-3 (CDH1 and $\mathrm{CDH} 3$, respectively). ${ }^{90}$ These genes are involved in maintaining epithelial barrier integrity, ${ }^{78}$ suggesting that a dysfunction in the epithelial barrier may predispose to UC.

It is possible that genetic risk factors may also contribute to the association between COPD and IBD. HHIP is also important in the development of the intestinal crypt axis, ${ }^{92}$ and further studies are required to identify whether this gene contributes to disease overlap between COPD and IBD. The diversity of gene susceptibility loci for both COPD and IBD suggests that susceptibility to these conditions may involve multiple genes and alleles that couple with environmental triggers to induce disease in some individuals.

\section{Disruption of the microbiome}

Bacterial colonization of the lower respiratory tract, although once controversial, is now known to influence the pathogenesis of COPD. ${ }^{93,94}$ The controversy was due to the classical view, borne largely from culture-based studies, of healthy lungs as a sterile environment. ${ }^{95,96}$ Advances in culture-independent techniques for microbial analysis have shown that the healthy lung is host to its own microbiome, which changes significantly during disease. ${ }^{97,98}$ Nevertheless, the precise role of the lung microbiome in COPD pathogenesis and the mechanisms that underpin infection-induced COPD exacerbations are poorly understood. ${ }^{94}$

It is also known that changes in the intestinal microbiome are associated with IBD; ${ }^{30,99,100}$ however, again, the nature of the shift in commensal populations is not well established. Indeed, it is certain that the microbiome contributes to both the initial inflammation and the chronic nature of IBD, but it is unclear whether commensals are the initiating factor. ${ }^{101}$ Regardless of the role in the initiation of IBD, chronic inflammation contributes to a loss of diversity in the microbiome, which seems to perpetuate the disease. ${ }^{99,101,102}$ In both COPD and IBD, the microbiomes of the lung and intestine have changes in the dominant species and a reduction in diversity, ${ }^{103}$ without decreases in microbial numbers. ${ }^{104}$ Whether these changes are a mechanism or consequence of inflammation is not understood, but clearly a healthy microbiome is important to both respiratory and gastrointestinal health.

\section{Epithelial barrier dysfunction}

Maintenance of epithelial barrier function is critical for maintaining the healthy state of the respiratory and gastrointestinal mucosa. This is because the epithelial barrier separates the interstitium and the underlying tissues from the milieu of antigenic material in the mucosal lumen. Consequently, loss-of-barrier function as a result of mucosal inflammation contributes to the chronic nature of these conditions, although it is not yet understood whether loss of function is a causative factor or a consequence of disease. COPD patients are particularly susceptible to bronchitis (inflammation of the bronchial mucosa), which develops as smoke exposure damages the airway epithelial barrier. Shaykhiev et al. ${ }^{105}$ have shown that smoking leads to downregulation of genes coding for tight junction and adherence proteins, which was more pronounced in smokers with COPD. In vitro studies examining the effect of cigarette smoke extract on primary bronchial epithelial cells have shown that the endogenous protease calpain, mediates degradation of tight junction complexes. ${ }^{106}$ Thus, smoking, the major environmental risk factor for COPD, promotes dysregulation of the pulmonary epithelial barrier.

Epithelial barrier dysfunction is a common feature of IBD. ${ }^{107}$ However, although this is well established, like COPD, it is unknown whether barrier dysfunction is a causative or a consequential factor. ${ }^{108,109}$ Certainly, in IBD, increased epithelial permeability promotes the progression of chronic inflammation. Soderholm et al. ${ }^{110}$ demonstrated that the epithelial tight junctions of non-inflamed intestinal tissues from CD patients were more susceptible to breakdown upon luminal antigenic stimulation. Epithelial breakdown allows the establishment of invasive bacterial infections, which are more characteristic of CD than UC. ${ }^{111}$ However, both UC and CD patients have high IgG titers against intestinal microbes, ${ }^{112}$ and both diseases show histopathological evidence for the loss of tight-junctional integrity, ${ }^{113-115}$ suggesting that epithelial dysfunction is important in both conditions.

\section{Pattern recognition receptors}

Pattern recognition receptors are a family of highly conserved proteins that are expressed by cells of the innate immune system. They recognize components termed "pattern-associated molecular patterns" of microorganisms, cellular stress signals, 
and damaged tissues. They may be membrane bound or cytoplasmic and, when activated, induce production and secretion of inflammatory mediators and signaling molecules. Two pattern recognition receptors families known to be important in the mucosal inflammatory response are the cytoplasmic NOD family of receptors and the membrane-bound Toll-like receptor (TLR) family. ${ }^{116-118}$

COPD patients are known to be at an increased risk of pulmonary infection, leading to inflammatory exacerbations of their disease; however, the mechanisms that underlie this increased risk are not well understood. ${ }^{119}$ Kinose et al. ${ }^{87}$ have recently identified increases in the prevalence of the NOD2 rs1077861 single-nucleotide polymorphism (SNP) in COPD patients. NOD2 recognizes muramyl dipeptide, an element of peptidoglycan, which is an important component of the cell wall of virtually all bacteria. This SNP causes a conformational change in NOD2 and leads to a series of downstream interactions that culminate in nuclear factor- $\kappa \mathrm{B}$ activation and an enhanced inflammatory cytokine response upon stimulation. Although baseline NOD2 expression was unaltered in COPD patients, the SNP was associated with increased COPD disease severity measured by reduced lung function. ${ }^{87}$ The mechanism for the involvement of the SNP in COPD pathology has yet to be fully characterized.

NOD2 is also strongly associated with CD, whereby a defect in NOD2 signaling leads to impaired epithelial barrier function, increased IL-1 $\beta$, and an overcompensating TLR2 response, and promotes increases in serum IL-12. ${ }^{79,117}$ NOD2 mutations are present in $15 \%$ of the $C D$ population, and a NOD2 SNP has recently been associated with smoking and CD. ${ }^{120}$ Although Kinose et al. did not examine TLR2 or IL-12 in the COPD study, IL-12 has been shown to be associated with increased CD8 cytotoxic T-cell and natural killer (NK) cell activation in COPD patients and mouse models, ${ }^{121,122}$ although whether this is related to NOD2 polymorphisms, requires further investigation. NOD2 may therefore be a common link between COPD and CD, with polymorphisms identified in COPD and CD populations, including an association with smoking and CD.

TLRs that recognize viral and bacterial proteins maintain mucosal homeostasis, and genetic variants of TLRs have been identified in COPD and IBD. ${ }^{18,123-126}$ Certainly, infection has a prominent role in COPD pathogenesis, and TLR2, which recognizes a range of bacterial and yeast proteins, has reduced expression and responsiveness to lipopolysaccharide (LPS) in alveolar macrophages from COPD patients and smokers. ${ }^{127}$ This suggests that there is a defect in the mucosal innate response in COPD. Conversely, TLR2 was shown to be upregulated in peripheral blood monocytes from COPD patients compared with healthy controls, ${ }^{124}$ perhaps indicating the presence of systemic inflammation in these patients. Although certain TLR2 polymorphisms are linked to increased infection, they do not seem to be associated with COPD. ${ }^{128}$ Thus, the exact nature and defects of TLR2 responses in COPD remain unclear. TLR4, which recognizes LPS, promotes COPD pathogenesis, although the pathways involved seem to be complex. ${ }^{126}$ Investigation of murine models indicates that TLR4 is involved in the development of smoke-induced inflammatory responses. ${ }^{129}$ This inflammatory response was driven by IL- $1 \beta$ secretion from macrophages and neutrophil recruitment to lung tissue. Smoke exposure also drives TLR4-dependent IL-8 production in monocyte-derived macrophages. ${ }^{130}$ In both of these studies, smoke-induced TLR4 activation was independent of LPS.

Both TLR2 and TLR4 were found to be induced in the colonic mucosa of pediatric IBD patients. ${ }^{131}$ Furthermore, Canto et al. ${ }^{132}$ identified an increase in TLR2 expression on peripheral blood monocytes, which was associated with elevated circulating tumor necrosis factor- $\alpha$ (TNF- $\alpha$ ) concentrations in active UC and CD. This suggests that, like COPD, systemic inflammation may be involved is IBD pathogenesis. The D299G and T399I SNPs of TLR4 have been shown to be associated with both UC and CD, ${ }^{133-135}$ whereas T399I has also been identified in COPD patients, ${ }^{136}$ suggesting a possible common link. Although the functional consequences of these gene variants are not yet fully appreciated, it is known that inflammatory cytokine signaling results in increased TLR4 expression on macrophages from the intestinal epithelium and lamina propria in both UC and CD resulting in increased responsiveness to LPS. ${ }^{137,138}$ Thus, TLR4 may have a common role in mucosal inflammatory disease, whereby an inflammatory insult coupled with TLR4 gene variations results in hypersensitivity to LPS and an exaggerated immune response in the lung or intestine.

\section{POTENTIAL MECHANISMS OF ORGAN CROSS-TALK}

Despite the similarities in the physiology of the respiratory and gastrointestinal mucosal organs, the common risk factors involved in the development of COPD and IBD and the incidences of inflammatory cross-talk between the two organs in disease, no mechanism has been identified for pulmonary-intestinal organ cross-talk. Although the respiratory and gastrointestinal tracts both share components of the common mucosal immune system, the pathways involved in crosstalk may be multifactorial, like COPD and IBD themselves (Figure 1).

\section{Protease regulation in COPD and IBD}

There is evidence that dysregulation of protease activity may have a role in both COPD and IBD. Increased levels of the proteases that break down connective tissue components have been identified in COPD patients and modeled in animals. ${ }^{139}$ Of particular interest is the matrix metalloproteinase (MMP) family of proteases, which has a role in the digestion of collagen, elastin, fibronectin, and gelatin, key components in mucosal structural integrity. ${ }^{140}$ Increased levels of epithelial and leukocyte MMP-2, MMP-9, and MMP-12 have been associated with the pathogenesis of COPD ${ }^{139,141,142}$ and IBD, ${ }^{143-146}$ which may contribute to a "runaway remodeling" process.

The role of A1AT in COPD is established; however, the prevalence of A1AT in IBD is debatable. A1AT neutralizes proteases 


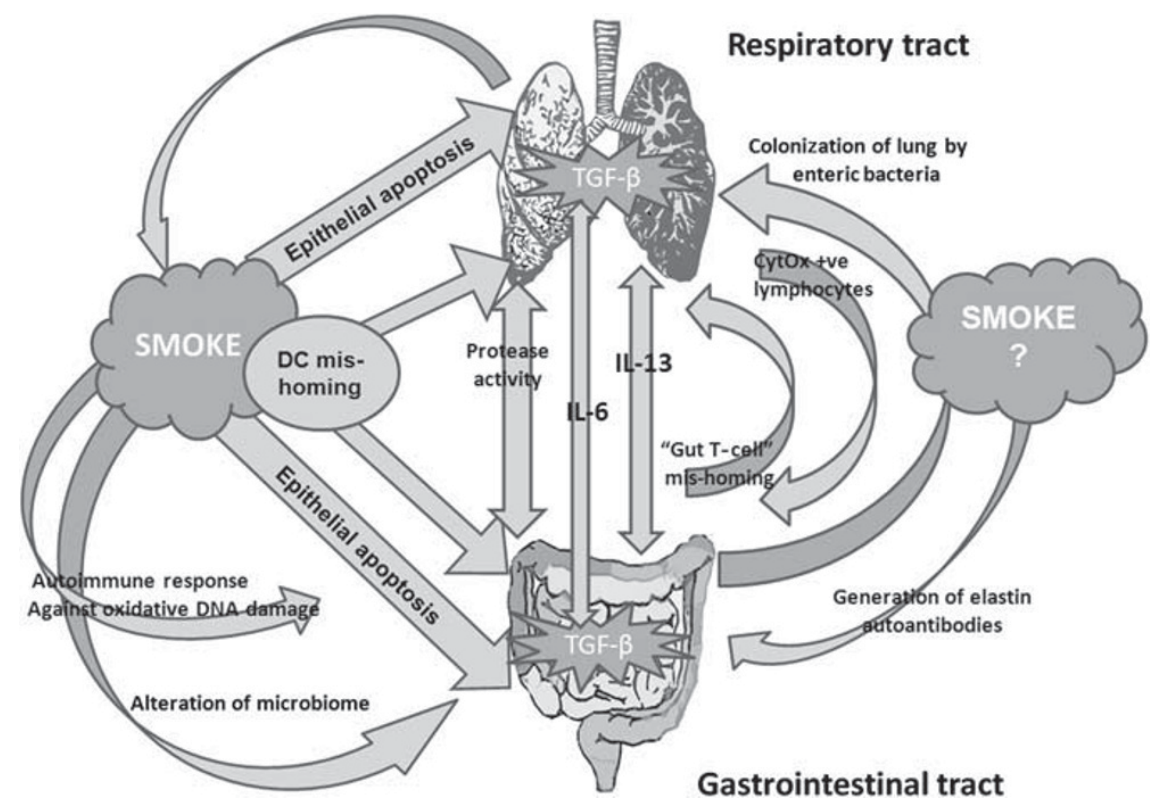

Figure 1 Possible mechanisms of respiratory-gastrointestinal cross-talk include overproduction of proteases during excessive inflammation, changes in immune cell function, including increases in cytochrome oxidase (CytOx) expressing lymphocytes and gut-originating T-cell mis-homing. Cigarette smoke exposure may have a role in organ cross-talk by affecting these processes, and/or by causing mis-homing of dendritic cells (DCs) and epithelial cell apoptosis in respiratory or gastrointestinal tissues. Smoke exposure may also lead to changes in the microbiome, promoting growth of enteric bacteria in the lung or altering the microbiome in the intestine that induces inflammatory responses. Inflammation may lead to the production of autoimmune antibodies against the ubiquitous mucosal protein elastin or autoimmune responses against antigens produced during smoke-induced oxidative DNA damage. Systemic IL-6, in conjunction with localized TGF- $\beta$, may drive cross-organ Th17-polarized inflammation. Systemic IL-13 may drive aberrant NKT and macrophage responses across organs. IL-6, interleukin-6; TGF- $\beta$, transforming growth factor- $\beta$.

involved in tissue remodeling, such as neutrophil elastase ${ }^{147}$ and MMP-12. ${ }^{148}$ Deficiencies in A1AT production promotes extensive tissue damage during mucosal inflammation as the tissue remodeling process progresses unchecked. Deficiency of A1AT leads to the development of emphysema and COPD. ${ }^{149,150}$ Owing to its role in the remodeling of inflamed tissue, fecal A1AT levels are commonly used as a marker for disease severity in CD patients. ${ }^{151,152}$ This suggests that that lack of A1AT does not promote the development of CD. Although some studies have suggested higher levels of A1AT in UC patients, ${ }^{153,154}$ there is a higher prevalence of the allele linked to A1AT deficiency (PiZ) among the UC population, ${ }^{153}$ and UC patients with this allele develop more severe forms of colitis. ${ }^{154}$ Further work is required to address this divergence.

\section{Immune cell homing and systemic factors}

Both COPD and IBD are considered to be systemic inflammatory diseases and peripheral lymphocyte activity may contribute to pathogenesis. ${ }^{36,155-158}$ During inflammation, the bronchusassociated lymphoid tissue regulates lymphocyte trafficking from the lung tissue through the general circulation. ${ }^{18}$ This mirrors the role of the gut-associated lymphoid tissue and both lung and intestinal lymphocytes migrate to other mucosal sites as part of the common mucosal immune system. ${ }^{159}$ It is possible that this trafficking, although functioning primarily as a common host mucosal defense, may be responsible for extra-organ inflammation associated with COPD and IBD.
In the healthy state, lymphocytes continuously migrate through the circulatory system, entering and exiting the tissue in response to antigen exposure. To control trafficking of lymphocytes through tissues, these cells express unique homing receptors, which are specific for corresponding ligands on their target tissues. Thus, through a combination of homing molecules and specific receptor-ligand interactions, lymphocytes will return to their tissue of origin during an immune response. ${ }^{160,161}$ The subtype and phenotype of circulating lymphocytes in COPD patients have not been well characterized. ${ }^{155}$ However, there is evidence of abnormal function in peripheral lymphocytes that may contribute to extrapulmonary disease in COPD patients. Sauleda et al. ${ }^{162}$ showed increased cytochrome oxidase (CytOx) activity in the circulating lymphocytes of COPD patients, which correlated with increased CytOx detected in wasting skeletal muscle that is commonly associated with COPD. Interestingly, this increased oxidative response in circulating lymphocytes is also observed in other chronic inflammatory diseases, such as asthma and rheumatoid arthritis, but whether these same responses occur in IBD is unknown.

For IBD patients, the selectivity of lymphocyte-endothelial interaction is lost. Salmi et al. ${ }^{163}$ showed that in IBD patients, the expression of homing receptors in intestinal lymphocytes did not confer tissue specificity. These altered homing properties may contribute to the extraintestinal manifestations of IBD. It is known that gut-derived lymphocytes possess the capacity to bind to synovial ${ }^{164}$ and hepatic ${ }^{165}$ tissue, possibly accounting 
for the manifestations of IBD observed in these organs. This mis-homing of lymphocytes is believed to contribute to ocular and dermatological extraintestinal manifestations of IBD. ${ }^{161}$ Whether this same phenomenon contributes to the lung pathologies observed in IBD is unknown. Increased lymphocyte populations have been observed in the bronchoalveolar lavage (BAL) of IBD patients, ${ }^{166,167}$ and analysis of the sputum of IBD patients showed that $65 \%$ had an increased CD4/CD8 T-cell ratio in the lung tissue. ${ }^{168}$ Whether this represents a further example of lymphocyte mis-homing involved in the pulmonary manifestations of IBD has yet to be confirmed.

It is possible that inhalation of smoke affects gut lymphocyte homing and promotes an inappropriate immune response. Smoke exposure is known to affect T-cell trafficking through altered chemotactic chemokine levels. ${ }^{169,170}$ Smoke inhalation also seems to affect the homing properties and maturation of myeloid dendritic cells (DCs), ${ }^{171-174}$ which are key antigen-presenting cells in mucosal immune responses. The result is a rapid accumulation of myeloid DCs in the airways of smokers, ${ }^{171}$ which may be a result of a reduced capacity of myeloid DCs to migrate to the lymph node. ${ }^{171,172} \mathrm{~A}$ recent animal study has similarly shown that smoke inhalation results in the accumulation of DCs in the intestinal Peyer's patches of wild-type mice, although unlike the airways, this does not seem to be dependent on changes in the expression of the DC-homing molecule CCR6. ${ }^{175}$ The increase in DCs was accompanied by a similar accumulation of CD4 $+\mathrm{T}$ cells and an apparent increase in apoptosis of the cells overlying the follicle-associated epithelial tissue of the intestine.

This loss in epithelial barrier may lead to increased antigen presentation and promote an intestinal inflammatory response. A caveat to this study was the use of a whole body smoke exposure model, which may not induce the same physiological consequence as inhaled smoke. Erosion of the epithelial layer overlying the follicle-associated epithelial tissue has been observed in CD patient biopsies. ${ }^{176}$ Although no data on smoking status of these patients exist, smoke-induced epithelial apoptosis is one possible mechanism for the development of these erosions. Thus, smoking may induce an overall increase in antigenic presentation in the intestines, which may contribute to IBD pathogenesis.

Circulating TNF- $\alpha$ has been strongly implicated in comorbidities associated with $\mathrm{COPD}^{51}$ and has a central role in the progression of $\mathrm{CD} .{ }^{177}$ Although anti-TNF therapies do not seem to provide therapeutic relief in $\mathrm{COPD},{ }^{51}$ they have been relatively successful for inducing remission in CD. ${ }^{178-180}$ Whether this is due to the nature of the damage in COPD or the efficacy of TNF therapy requires further investigation. Studies in transgenic mouse models that overexpress TNF- $\alpha$, the TNF $\Delta$ ARE mouse model, have shown the development of spontaneous Crohn's-like ileitis and proximal colitis. ${ }^{181}$ Although ocular and synovial involvement has been observed, there have been no reports of respiratory disease in this model. However, as with pulmonary manifestations of IBD, the airway involvement may be subclinical and histopathological and lung function studies may be required.
IL-6 has a role in the acute phase response to inflammation and has been implicated in the pathogenesis of both COPD ${ }^{182,183}$ and IBD. ${ }^{184,185}$ IL-6 is systemically elevated in patients with emphysema and has been shown be associated with apoptosis in the pulmonary tissue. ${ }^{182,183}$ Importantly, IL-6, in combination with transforming growth factor- $\beta$, is a major factor in the development of the Th17 subset of T-helper cells. ${ }^{18,186}$ Th17 cells are a distinct effector T-cell subset that secretes IL-17A, IL-17F, IL-21, IL-22, IL-26, and TNF- $\alpha$ and promote neutrophil chemotaxis. ${ }^{118,187-190}$ Recent work has identified increased peripheral Th17 cells in COPD patients. ${ }^{186}$

IL- 6 and Th17 cells are also associated with both CD and UC, ${ }^{185,191}$ and high levels of IL- 6 and Th17-associated cytokines have been identified in both the blood ${ }^{185}$ and the inflamed and non-inflamed mucosa ${ }^{191,192}$ of IBD patients. Moreover, blockade of the IL-6 pathway is therapeutic in animal models. The fact that IL-6 is elevated in the non-inflamed intestinal mucosa of IBD patients, without causing tissue damage, may suggest that a secondary tissue insult is required. As transforming growth factor- $\beta$ regulates mucosal tissue remodeling and is strongly associated with COPD and IBD, it is conceivable that increased systemic IL- 6 , coupled with transforming growth factor- $\beta$ production at the mucosal surface (due to smoke damage in the lungs of an IBD patient or an intestinal infection in an COPD patients), may lead to the development of a Th17-polarized inflammatory response at a secondary organ.

IL-13 is likely to contribute to COPD progression ${ }^{193}$ and mutations in the IL-13 promoter may promote this pathogenesis. ${ }^{194}$ T-cell receptor-invariant NK cells or DCs, activated by bacterial or viral infection in the airways, secrete IL-13, which activates macrophages. ${ }^{193,195-197}$ This in turn causes further IL-13 production, which leads to STAT (signal-transducer and activator of transcription)6-dependent goblet cell hyperplasia, smooth muscle hyper-responsiveness, and airway remodeling. ${ }^{188,198}$

IL-13 also has a role in the pathogenesis of UC, but does not seem to be involved in CD. ${ }^{199}$ In UC, it appears to be the aberrant stimulation of the immune response by the microbiome, which results in direct invariant NK cell cytotoxic action on the epithelium and secretion of IL-13-driving epithelial barrier dysfunction and apoptosis, and enhancement of NKC toxicity. ${ }^{199,200}$ Like COPD, STAT6 is an important mediator for the action of IL-13 on the epithelium, ${ }^{201}$ and the STAT6 pathway is a potential therapeutic target in both conditions. Whether these pathways act systemically in COPD and IBD is unknown, although serum IL-13 is increased in COPD, ${ }^{194}$ possibly driving aberrant NKT and macrophage responses across organs.

\section{Interaction of the respiratory and intestinal microbiomes}

COPD sufferers have an altered lung microbiome compared with healthy individuals, including "healthy" smokers. ${ }^{103}$ This does not exclude the possibility that smoking influences the lung microbiome. Smoking has been shown to restrict the ability of alveolar macrophages to phagocytose and kill bacteria. ${ }^{202}$ This suggests that smoking may lead to a defect in immunoregulation of the lung microbiome. There is evidence that components of 
the enteric microflora, specifically Gram-negative bacilli, may also make up a component of the lung microflora. ${ }^{203,204}$ These bacteria are resistant to cigarette smoke ${ }^{205}$ and may contribute to severe exacerbations of COPD. ${ }^{204}$ Furthermore, inappropriate immune responses against intestinal microflora are widely accepted to be a critical factor in the ongoing inflammation associated with IBD. Thus, there exists the possibility that the immune response against commensal microflora observed in IBD patients, may not be restricted to the gastrointestinal tract, but may also be directed toward enteric bacteria present in the lung microflora.

There have been no definitive studies on the effect of smoking on the respiratory or intestinal microbiome. This is especially surprising given cigarette smoke is known to selectively inhibit bacterial growth, favoring a Gram-negative bacilli population. ${ }^{205}$ It is possible that smoke-induced changes to the intestinal microbiome may promote the increased risk of IBD observed in COPD sufferers. There is growing interest in how diet and nutrition may influence the human microbiome and interplay with the immune system and ultimately human health. 206,207 Fecal bacteriotherapy, whereby the microflora of a healthy patient is transplanted to a colic patient, has shown promise in case studies, as a treatment for UC. ${ }^{102,208,209}$ This suggests that the composition of the microbiome has an important role in the intestinal inflammation, and restoration of a "healthy microbiome" can promote remission of disease. Although ultimately conjecture, it is conceivable that smoking may disrupt the "healthy microbiome" and therefore link, smoking and COPD to IBD. This could also account for the familial link of COPD and IBD observed by Ekbom et al. ${ }^{39}$ as there is a familial link to the make-up of an individuals microbiome and genetics have a role in microbiome development. ${ }^{210,211}$

\section{Autoimmunity}

There is some evidence to suggest that COPD has an autoimmune element, which leads to disease progression and relapse. ${ }^{212}$ Key to this concept are the observations that only some smokers develop COPD and that the clinical features of COPD continue to increase in severity even after the cessation of smoking. This suggests that ongoing immune responses occur against elements other than cigarette smoke. Smoke-induced emphysema has been shown to generate an autoimmune response against elastins. ${ }^{140,213}$ In this proposed model, exposure to smoke antigens promotes an immune response that includes secretion of high levels of elastin proteases (elastases) from neutrophils and macrophages (e.g., neutrophil elastase, MMP-9, and MMP-12). ${ }^{214}$ The elastases degrade and fragment elastin proteins, to which the adaptive immune system mounts a response. ${ }^{140}$ As elastin is a ubiquitous protein in the mucosal tissue, an autoimmune response could lead to pathologies outside the lung, and may be a mechanism for intestinal pathologies associated with smoking.

Tzortzaki and Siafakas ${ }^{215}$ proposed that smoke-induced oxidative epithelial damage initiates the disease process in COPD through the initiation of autoimmune responses. In their proposed model, oxidative DNA damage to epithelial cells leads to phenotypic changes and recognition of these cells as "non-self" by pulmonary DCs. This results in a loss-of-barrier function as a T-cell response is initiated against the epithelium. Such autoimmune responses may affect the intestinal epithelium, or may be driven by smoke exposure at the intestinal mucosa.

It is generally accepted that $\mathrm{CD}$ is a disease with an autoimmune component. The prevailing hypothesis for the development of $\mathrm{CD}$ is that an initial infection or insult leads to an inappropriate immune response against the intestinal mucosa and/or commensal bacterial population. ${ }^{30,56}$ This leads to the recurring cycles of chronic inflammation that characterize $\mathrm{CD}$. UC also has a clear autoimmune element, although different to that of CD. ${ }^{216,217}$ Recent work has found that isoforms of human tropomyosin (hTM 1-5) are capable of inducing autoantibodies and T-cell responses in UC. ${ }^{218}$ Autoimmunity would also explain some elements of organ cross-talk in inflammatory disease. Immune responses against bacteria or conserved mucosal protein epitopes of the pulmonary and gastrointestinal tracts may explain cross-organ inflammation in COPD and IBD. Expression of hTM on extraintestinal organs may account for cross-organ inflammatory associations in UC, although hTM5, the trypomyosin with the strongest link to $\mathrm{UC}$, has not been identified in the lung tissue. ${ }^{218}$

\section{SUMMARY}

Both COPD and IBD are driven by inflammatory processes, are systemic diseases, and are epidemiologically linked. Given the consistent indications of the limited research to date, it is clear that comprehensive studies on the prevalence of intestinal involvement in COPD and pulmonary disease among IBD patients are required. The mechanisms that underpin the development of extra-organ inflammation in COPD and IBD patients are confounded by the complicated etiologies of these conditions. Both conditions share environmental triggers and have similar immune and physiological involvement. However, the diversity of the mechanisms that may be involved in the development of each condition suggests that cross-talk in these diseases may be a multi-faceted process involving multiple pathways (Figure 1). Our understanding of this area is largely based on epidemiological and clinical observations and there is a need for basic research to elucidate the associations and mechanisms involved. A better understanding of the nature of organ crosstalk in COPD and IBD will contribute to the elucidation of the etiologies of these conditions and may identify therapeutic strategies for mucosal inflammatory disease.

\section{ACKNOWLEDGMENTS}

SK has been supported by a Crohn's and Colitis Fellowship of America and is currently supported by funding from the National Health and Medical Research Council of Australia. NJT is supported by funding from the National Health and Medical Research Council of Australia and the National Institute of Health of the United States of America. PMH is supported by funding from the National Health and Medical Research Council of Australia and the Australian Research Council.

\section{DISCLOSURE}

The authors declared no conflict of interest.

(C) 2012 Society for Mucosal Immunology 


\section{REFERENCES}

1. WHO. The global burden of disease: 2004 update. World Health Organisation (2008).

2. Lakatos, P.L. Recent trends in the epidemiology of inflammatory bowel diseases: up or down? World J. Gastroenterol. 12, 6102-6108 (2006).

3. Loftus, E.V. Jr Clinical epidemiology of inflammatory bowel disease: incidence, prevalence, and environmental influences. Gastroenterology 126, 1504-1517 (2004).

4. Association ACsaC. The economic costs of Crohn's disease and ulcerative colitis. Access Economics Pty Limited (2007).

5. Kamm, M.A. Review article: chronic active disease and maintaining remission in Crohn's disease. Aliment. Pharmacol. Therapeut. 20, 102-105 (2004).

6. Holguin, F., Folch, E., Redd, S.C. \& Mannino, D.M. Comorbidity and mortality in COPD-related hospitalizations in the United States, 1979 to 2001. Chest 128, 2005-2011 (2005).

7. Mestecky, J. The common mucosal immune system and current strategies for induction of immune responses in external secretions. J. Clin. Immunol. 7, 265-276 (1987).

8. Mestecky, J., McGhee, J.R., Michalek, S.M., Arnold, R.R., Crago, S.S. \& Babb, J.L. Concept of the local and common mucosal immune response. Adv. Exp. Med. Biol. 107, 185-192 (1978).

9. Kuebler, W.M. Inflammatory pathways and microvascular responses in the lung. Pharmacol. Rep. 57 (Suppl), 196-205 (2005).

10. Labiris, N.R. \& Dolovich, M.B. Pulmonary drug delivery. Part I: physiological factors affecting therapeutic effectiveness of aerosolized medications. Br. J. Clin. Pharmacol. 56, 588-599 (2003).

11. Mason, K.L., Huffnagle, G.B., Noverr, M.C. \& Kao, J.Y. Overview of gut immunology. Adv. Exp. Med. Biol. 635, 1-14 (2008).

12. Takahashi, I. \& Kiyono, H. Gut as the largest immunologic tissue. JPEN J. Parenter. Enteral. Nutr. 23 (5 Suppl), S7-12 (1999).

13. Keely, S. et al. Hypoxia-inducible factor-dependent regulation of plateletactivating factor receptor as a route for gram-positive bacterial translocation across epithelia. Mol. Biol. Cell 21, 538-546 (2010).

14. Kominsky, D.J. et al. An endogenously anti-inflammatory role for methylation in mucosal inflammation identified through metabolite profiling. J. Immunol. 186, 6505-6514 (2011).

15. Matthay, M.A. Function of the alveolar epithelial barrier under pathologic conditions. Chest 105 (3 Suppl), 67S-74S (1994).

16. Keely, S., Rawlinson, L.A., Haddleton, D.M. \& Brayden, D.J. A tertiary amino-containing polymethacrylate polymer protects mucus-covered intestinal epithelial monolayers against pathogenic challenge. Pharm. Res. 25, 1193-1201 (2008).

17. Keely, S. et al. In vitro and ex vivo intestinal tissue models to measure mucoadhesion of poly (methacrylate) and $\mathrm{N}$-trimethylated chitosan polymers. Pharm. Res. 22, 38-49 (2005).

18. Holt, P.G. Development of bronchus associated lymphoid tissue (BALT) in human lung disease: a normal host defence mechanism awaiting therapeutic exploitation? Thorax 48, 1097-1098 (1993).

19. Forchielli, M.L. \& Walker, W.A. The role of gut-associated lymphoid tissues and mucosal defence. Br. J. Nutr. 93 (Suppl 1), S41-S48 (2005).

20. Shu, W., Lu, M.M., Zhang, Y., Tucker, P.W., Zhou, D. \& Morrisey, E.E. Foxp2 and Foxp1 cooperatively regulate lung and esophagus development. Development 134, 1991-2000 (2007).

21. Ramalho-Santos, M., Melton, D.A. \& McMahon, A.P. Hedgehog signals regulate multiple aspects of gastrointestinal development. Development 127, 2763-2772 (2000).

22. Roth, M. Pathogenesis of COPD. Part III. Inflammation in COPD. Int. J. Tuberc. Lung. Dis. 12, 375-380 (2008).

23. Vestbo, J. \& Hogg, J.C. Convergence of the epidemiology and pathology of COPD. Thorax 61, 86-88 (2006).

24. Yang, I.V. \& Schwartz, D.A. Epigenetic control of gene expression in the lung. Am. J. Respir. Crit. Care Med. 183, 1295-1301 (2011).

25. O'Reilly, M. et al. Persistent bronchiolar remodeling following brief ventilation of the very immature ovine lung. Am. J. Physiol. Lung Cell Mol. Physiol. 297, L992-L1001 (2009).

26. Horvat, J.C. et al. Early-life chlamydial lung infection enhances allergic airways disease through age-dependent differences in immunopathology. J. Allergy Clin. Immunol. 125, 617-625, 625 e611-625 e616 (2010).

27. Baumgart, D.C. \& Carding, S.R. Inflammatory bowel disease: cause and immunobiology. Lancet 369, 1627-1640 (2007).
28. Allez, M. \& Modigliani, R. Clinical features of inflammatory bowel disease. Curr. Opin. Gastroenterol. 16, 329-336 (2000).

29. Palnaes Hansen, C., Hegnhoj, J., Moller, A., Brauer, C., Hage, E. \& Jarnum, S. Ulcerative colitis and Crohn's disease of the colon. Is there a macroscopic difference? Ann. Chir. Gynaecol. 79, 78-81 (1990).

30. Sartor, R.B. Mechanisms of disease: pathogenesis of Crohn's disease and ulcerative colitis. Nat. Clin. Pract. Gastroenterol. Hepatol. 3, 390-407 (2006).

31. Tzanakis, N.E., Tsiligianni, I.G. \& Siafakas, N.M. Pulmonary involvement and allergic disorders in inflammatory bowel disease. World J. Gastroenterol. 16, 299-305 (2010).

32. Basseri, B., Enayati, P., Marchevsky, A. \& Papadakis, K.A. Pulmonary manifestations of inflammatory bowel disease: case presentations and review. J. Crohns Colitis 4, 390-397 (2010).

33. Black, H., Mendoza, M. \& Murin, S. Thoracic manifestations of inflammatory bowel disease. Chest 131, 524-532 (2007).

34. Fedorova, T.A. et al. The stomach and duodenum condition in patients with chronic obstructive lung diseases]. Klin. Med. (Mosk) 81, 31-33 (2003).

35. Benard, A., Desreumeaux, P., Huglo, D., Hoorelbeke, A., Tonnel, A.B. \& Wallaert, B. Increased intestinal permeability in bronchial asthma. J. Allergy Clin. Immunol. 97, 1173-1178 (1996).

36. Levine, J.B. \& Lukawski-Trubish, D. Extraintestinal considerations in inflammatory bowel disease. Gastroenterol. Clin. North Am. 24, 633-646 (1995).

37. Decramer, M. et al. COPD as a lung disease with systemic consequences-clinical impact, mechanisms, and potential for early intervention. COPD 5, 235-256 (2008).

38. Duricova, D., Pedersen, N., Elkjaer, M., Gamborg, M., Munkholm, P. \& Jess, T. Overall and cause-specific mortality in Crohn's disease: a metaanalysis of population-based studies. Inflamm. Bowel Dis. 16, 347-353 (2010).

39. Ekbom, A., Brandt, L., Granath, F., Lofdahl, C.G. \& Egesten, A. Increased risk of both ulcerative colitis and Crohn's disease in a population suffering from COPD. Lung 186, 167-172 (2008).

40. Jess, T. et al. Survival and cause specific mortality in patients with inflammatory bowel disease: a long term outcome study in Olmsted County, Minnesota, 1940-2004. Gut 55, 1248-1254 (2006).

41. Beloborodova, E.I., Akimova, L.A., Burkovskaia, B.A., Asanova, A.V. \& Semenenko, E.V. Activity of systemic inflammatory reaction in patients with chronic obstructive pulmonary disease in regard to small intestinal absorption function]. Ter. Arkh. 81, 19-23 (2009).

42. Kuzela, L. et al. Pulmonary complications in patients with inflammatory bowel disease. Hepatogastroenterology 46, 1714-1719 (1999).

43. Tzanakis, N. et al. Lung function in patients with inflammatory bowel disease. Respir. Med. 92, 516-522 (1998).

44. Tzanakis, N., Samiou, M., Bouros, D., Mouzas, J., Kouroumalis, E. \& Siafakas, N.M. Small airways function in patients with inflammatory bowel disease. Am. J. Respir. Crit. Care Med. 157, 382-386 (1998).

45. Songur, N. et al. Pulmonary function tests and high-resolution CT in the detection of pulmonary involvement in inflammatory bowel disease. J. Clin. Gastroenterol. 37, 292-298 (2003).

46. Douglas, J.G., McDonald, C.F., Leslie, M.J., Gillon, J., Crompton, G.K. \& McHardy, G.J. Respiratory impairment in inflammatory bowel disease: does it vary with disease activity? Respir. Med. 83, 389-394 (1989).

47. Ceyhan, B.B., Karakurt, S., Cevik, H. \& Sungur, M. Bronchial hyperreactivity and allergic status in inflammatory bowel disease. Respiration 70, 60-66 (2003).

48. Rabe, K.F. et al. Global strategy for the diagnosis, management, and prevention of chronic obstructive pulmonary disease: GOLD executive summary. Am. J. Respir. Crit. Care Med. 176, 532-555 (2007).

49. Hogg, J.C. et al. The nature of small-airway obstruction in chronic obstructive pulmonary disease. N. Engl. J. Med. 350, 2645-2653 (2004).

50. Stampfli, M.R. \& Anderson, G.P. How cigarette smoke skews immune responses to promote infection, lung disease and cancer. Nat. Rev. Immunol. 9, 377-384 (2009).

51. Sevenoaks, M.J. \& Stockley, R.A. Chronic obstructive pulmonary disease, inflammation and co-morbidity-a common inflammatory phenotype? Respir. Res. 7, 70 (2006).

52. Lundback, B. et al. Not 15 but $50 \%$ of smokers develop COPD? Report from the Obstructive Lung Disease in Northern Sweden Studies. Respir. Med. 97, 115-122 (2003). 
53. Hallberg, J. et al. Genetic and environmental influence on lung function impairment in Swedish twins. Respir. Res. 11, 92 (2010).

54. Sandford, A.J., Joos, L. \& Pare, P.D. Genetic risk factors for chronic obstructive pulmonary disease. Curr. Opin. Pulm. Med. 8, 87-94 (2002).

55. Somerville, K.W., Logan, R.F., Edmond, M. \& Langman, M.J. Smoking and Crohn's disease. Br. Med. J. (Clin. Res. Ed.) 289, 954-956 (1984).

56. Danese, S. \& Fiocchi, C. Etiopathogenesis of inflammatory bowel diseases. World J. Gastroenterol. 12, 4807-4812 (2006).

57. Birrenbach, T. \& Böcker, U. Inflammatory bowel disease and smoking: a review of epidemiology, pathophysiology, and therapeutic implications. Inflamm. Bowel Dis. 10, 848-859 (2004).

58. Cosnes, J., Nion-Larmurier, I., Afchain, P., Beaugerie, L. \& Gendre, J.P. Gender differences in the response of colitis to smoking. Clin. Gastroenterol. Hepatol. 2, 41-48 (2004).

59. Cosnes, J. Tobacco and IBD: relevance in the understanding of disease mechanisms and clinical practice. Best Pract. Res. Clin. Gastroenterol. 18, 481-496 (2004).

60. Logan, R.F., Edmond, M., Somerville, K.W. \& Langman, M.J. Smoking and ulcerative colitis. Br. Med. J. (Clin Res Ed) 288, 751-753 (1984).

61. Bridger, S., Lee, J.C., Bjarnason, I., Jones, J.E. \& Macpherson, A.J. In siblings with similar genetic susceptibility for inflammatory bowel disease, smokers tend to develop Crohn's disease and non-smokers develop ulcerative colitis. Gut 51, 21-25 (2002).

62. Beaugerie, L., Massot, N., Carbonnel, F., Cattan, S., Gendre, J.P. \& Cosnes, J. Impact of cessation of smoking on the course of ulcerative colitis. Am. J. Gastroenterol. 96, 2113-2116 (2001).

63. Silverstein, M.D., Lashner, B.A. \& Hanauer, S.B. Cigarette smoking and ulcerative colitis: a case-control study. Mayo Clin. Proc. 69, 425-429 (1994).

64. Boyko, E.J., Koepsell, T.D., Perera, D.R. \& Inui, T.S. Risk of ulcerative colitis among former and current cigarette smokers. N. Engl. J. Med. 316, 707-710 (1987).

65. Yang, S.K., Loftus, E.V. \& Sandborn, W.J. Epidemiology of inflammatory bowel disease in Asia. Inflamm. Bowel Dis. 7, 260-270 (2001).

66. Ahuja, V. \& Tandon, R.K. Inflammatory bowel disease in the Asia-Pacific area: a comparison with developed countries and regional differences. J. Dig. Dis. 11, 134-147 (2010).

67. Sun, Y.P., Wang, H.H., He, Q. \& Cho, C.H. Effect of passive cigarette smoking on colonic alpha7-nicotinic acetylcholine receptors in TNBS-induced colitis in rats. Digestion 76, 181-187 (2007).

68. Galeazzi, F., Blennerhassett, P.A., Qiu, B., O’Byrne, P.M. \& Collins, S.M. Cigarette smoke aggravates experimental colitis in rats. Gastroenterology 117, 877-883 (1999).

69. Guo, X., Ko, J.K., Mei, Q.B. \& Cho, C.H. Aggravating effect of cigarette smoke exposure on experimental colitis is associated with leukotriene B(4) and reactive oxygen metabolites. Digestion 63, 180-187 (2001).

70. de Serres, F.J., Blanco, I. \& Fernandez-Bustillo, E. Estimating the risk for alpha-1 antitrypsin deficiency among COPD patients: evidence supporting targeted screening. COPD 3, 133-139 (2006).

71. Stein, P.K. et al. Heart rate variability reflects severity of COPD in $\mathrm{PiZ}$ alpha1-antitrypsin deficiency. Chest 113, 327-333 (1998).

72. Pillai, S.G. et al. A genome-wide association study in chronic obstructive pulmonary disease (COPD): identification of two major susceptibility loci. PLoS Genet. 5, e1000421 (2009).

73. Van Durme, Y.M. et al. Hedgehog-interacting protein is a COPD susceptibility gene: the Rotterdam Study. Eur. Respir. J. 36, 89-95 (2010).

74. Wilk, J.B. et al. A genome-wide association study of pulmonary function measures in the Framingham Heart Study. PLoS Genet. 5, e1000429 (2009).

75. Chappell, S.L. et al. The role of IREB2 and transforming growth factor beta-1 genetic variants in COPD: a replication case-control study. BMC Med. Genet. 12, 24 (2011).

76. DeMeo, D.L. et al. Integration of genomic and genetic approaches implicates IREB2 as a COPD susceptibility gene. Am. J. Hum. Genet. 85, 493-502 (2009).

77. Bengtson, M.B. et al. Clustering in time of familial IBD separates ulcerative colitis from Crohn's disease. Inflamm. Bowel Dis. 15, 1867-1874 (2009).

78. Cho, J.H. \& Brant, S.R. Recent insights into the genetics of inflammatory bowel disease. Gastroenterology 140, 1704-1712 e1702 (2011).
79. Strober, W., Kitani, A., Fuss, I., Asano, N. \& Watanabe, T. The molecular basis of NOD2 susceptibility mutations in Crohn's disease. Mucosal. Immunol. 1 (Suppl 1), S5-S9 (2008).

80. Ogura, Y. et al. A frameshift mutation in NOD2 associated with susceptibility to Crohn's disease. Nature 411, 603-606 (2001).

81. Hugot, J.P. et al. Association of NOD2 leucine-rich repeat variants with susceptibility to Crohn's disease. Nature 411, 599-603 (2001).

82. Prescott, N.J. et al. A nonsynonymous SNP in ATG16L1 predisposes to ileal Crohn's disease and is independent of CARD15 and IBD5. Gastroenterology 132, 1665-1671 (2007).

83. Cummings, J.R. et al. Confirmation of the role of ATG16L1 as a Crohn's disease susceptibility gene. Inflamm. Bowel Dis. 13, 941-946 (2007).

84. Cotterill, L. et al. Replication and meta-analysis of 13,000 cases defines the risk for interleukin-23 receptor and autophagy-related 16-like 1 variants in Crohn's disease. Can. J. Gastroenterol. 24, 297-302 (2010).

85. Yano, T. \& Kurata, S. An unexpected twist for autophagy in Crohn's disease. Nat. Immunol. 10, 134-136 (2009).

86. Parkes, M. et al. Sequence variants in the autophagy gene IRGM and multiple other replicating loci contribute to Crohn's disease susceptibility. Nat. Genet. 39, 830-832 (2007).

87. Kinose, D. et al. A NOD2 gene polymorphism is associated with the prevalence and severity of chronic obstructive pulmonary disease in a Japanese population. Respirology; advance online publication 22 September 2011; doi:10.1111/j.1440-1843.2011.02069.x (e-pub ahead of print).

88. Cottone, M., Bunce, M., Taylor, C.J., Ting, A. \& Jewell, D.P. Ulcerative colitis and HLA phenotype. Gut 26, 952-954 (1985).

89. Nahir, M., Gideoni, O., Eidelman, S. \& Barzilai, A. Letter: HLA antigens in ulcerative colitis. Lancet 2, 573 (1976).

90. Barrett, J.C. et al. Genome-wide association study of ulcerative colitis identifies three new susceptibility loci, including the HNF4A region. Nat. Genet. 41, 1330-1334 (2009).

91. Fisher, S.A. et al. Genetic determinants of ulcerative colitis include the ECM1 locus and five loci implicated in Crohn's disease. Nat. Genet. 40, 710-712 (2008).

92. Madison, B.B., Braunstein, K., Kuizon, E., Portman, K., Qiao, X.T. \& Gumucio, D.L. Epithelial hedgehog signals pattern the intestinal crypt-villus axis. Development 132, 279-289 (2005).

93. Murphy, T.F. \& Sethi, S. Bacterial infection in chronic obstructive pulmonary disease. Am. Rev. Respir. Dis. 146, 1067-1083 (1992).

94. Zalacain, R. et al. Predisposing factors to bacterial colonization in chronic obstructive pulmonary disease. Eur. Respir. J. 13, 343-348 (1999).

95. Baughman, R.P., Thorpe, J.E., Staneck, J., Rashkin, M. \& Frame, P.T. Use of the protected specimen brush in patients with endotracheal or tracheostomy tubes. Chest 91, 233-236 (1987).

96. Kahn, F.W. \& Jones, J.M. Diagnosing bacterial respiratory infection by bronchoalveolar lavage. J. Infect. Dis. 155, 862-869 (1987).

97. Harris, J.K. et al. Molecular identification of bacteria in bronchoalveolar lavage fluid from children with cystic fibrosis. Proc. Natl Acad. Sci. USA 104, 20529-20533 (2007).

98. Huang, Y.J. et al. A persistent and diverse airway microbiota present during chronic obstructive pulmonary disease exacerbations. OMICS 14, 9-59 (2010).

99. Frank, D.N. et al. Disease phenotype and genotype are associated with shifts in intestinal-associated microbiota in inflammatory bowel diseases. Inflamm. Bowel Dis. 17, 179-184 (2010).

100. Sartor, R.B. Genetics and environmental interactions shape the intestinal microbiome to promote inflammatory bowel disease versus mucosal homeostasis. Gastroenterology 139, 1816-1819 (2010).

101. Salzman, N.H. \& Bevins, C.L. Negative interactions with the microbiota: IBD. Adv. Exp. Med. Biol. 635, 67-78 (2008).

102. Borody, T.J., Warren, E.F., Leis, S., Surace, R. \& Ashman, O. Treatment of ulcerative colitis using fecal bacteriotherapy. J. Clin. Gastroenterol. 37, 42-47 (2003).

103. Erb-Downward, J.R. et al. Analysis of the lung microbiome in the "healthy" smoker and in COPD. PLoS One 6, e16384 (2011).

104. Schultsz, C., Van Den Berg, F.M., Ten Kate, F.W., Tytgat, G.N. \& Dankert, $J$. The intestinal mucus layer from patients with inflammatory bowel disease harbors high numbers of bacteria compared with controls. Gastroenterology 117, 1089-1097 (1999).

105. Shaykhiev, R. et al. Cigarette smoking reprograms apical junctional complex molecular architecture in the human airway epithelium in vivo. Cell. Mol. Life Sci. 68, 877-892 (2011). 
106. Heijink, I.H., Brandenburg, S.M., Postma, D.S. \& van Oosterhout, A.J. Cigarette smoke impairs airway epithelial barrier function and cell-cell contact recovery. Eur. Respir J.; advance online publication 20 July 2011; doi:10.1183/09031936.00193810.

107. Rask-Madsen, J., Hammersgaard, E.A. \& Knudsen, E. Rectal electrolyte transport and mucosal permeability in ulcerative colitis and Crohn's disease. J. Lab. Clin. Med. 81, 342-353 (1973).

108. McGuckin, M.A., Eri, R., Simms, L.A., Florin, T.H. \& Radford-Smith, G. Intestinal barrier dysfunction in inflammatory bowel diseases. Inflamm. Bowel Dis. 15, 100-113 (2009).

109. Yu, Y., Sitaraman, S. \& Gewirtz, A.T. Intestinal epithelial cell regulation of mucosal inflammation. Immunol. Res. 29, 55-68 (2004).

110. Soderholm, J.D. et al. Augmented increase in tight junction permeability by luminal stimuli in the non-inflamed ileum of Crohn's disease. Gut $\mathbf{5 0}$, 307-313 (2002).

111. Martin, H.M. et al. Enhanced Escherichia coli adherence and invasion in Crohn's disease and colon cancer. Gastroenterology 127, 80-93 (2004).

112. Furrie, E., Macfarlane, S., Cummings, J.H. \& Macfarlane, G.T. Systemic antibodies towards mucosal bacteria in ulcerative colitis and Crohn's disease differentially activate the innate immune response. Gut 53, 91-98 (2004).

113. Lunardi, C. et al. Antiflagellin antibodies recognize the autoantigens Tolllike receptor 5 and Pals 1-associated tight junction protein and induce monocytes activation and increased intestinal permeability in Crohn's disease. J. Intern. Med. 265, 250-265 (2009).

114. Marin, M.L., Greenstein, A.J., Geller, S.A., Gordon, R.E. \& Aufses, A.H. Jr A freeze fracture study of Crohn's disease of the terminal ileum: changes in epithelial tight junction organization. Am. J. Gastroenterol. 78, 537-547 (1983).

115. Schmitz, H. et al. Altered tight junction structure contributes to the impaired epithelial barrier function in ulcerative colitis. Gastroenterology 116, 301-309 (1999).

116. Bauer, S., Muller, T. \& Hamm, S. Pattern recognition by Toll-like receptors. Adv. Exp. Med. Biol. 653, 15-34 (2009).

117. Eckmann, L. \& Karin, M. NOD2 and Crohn's disease: loss or gain of function? Immunity 22, 661-667 (2005).

118. Kaiko, G.E., Horvat, J.C., Beagley, K.W. \& Hansbro, P.M. Immunological decision-making: how does the immune system decide to mount a helper T-cell response? Immunology 123, 326-338 (2008).

119. Crim, C. et al. Pneumonia risk in COPD patients receiving inhaled corticosteroids alone or in combination: TORCH study results. Eur. Respir J. 34, 641-647 (2009).

120. van der Heide, F., Nolte, I.M., Kleibeuker, J.H., Wijmenga, C., Dijkstra, G. \& Weersma, R.K. Differences in genetic background between active smokers, passive smokers, and non-smokers with Crohn's disease. Am. J. Gastroenterol. 105, 1165-1172 (2010).

121. Freeman, C.M. et al. Cytotoxic potential of lung CD8(+) T cells increases with chronic obstructive pulmonary disease severity and with in vitro stimulation by IL-18 or IL-15. J. Immunol. 184, 6504-6513 (2010).

122. Motz, G.T. et al. Chronic cigarette smoke exposure primes NK cell activation in a mouse model of chronic obstructive pulmonary disease. J. Immunol. 184, 4460-4469 (2010).

123. Kathrani, A. et al. Polymorphisms in the TLR4 and TLR5 gene are significantly associated with inflammatory bowel disease in German shepherd dogs. PLoS One 5, e15740 (2010).

124. Pons, J. et al. Expression of Toll-like receptor 2 is up-regulated in monocytes from patients with chronic obstructive pulmonary disease. Respir. Res. 7, 64 (2006).

125. Sabroe, I., Whyte, M.K., Wilson, A.G., Dower, S.K., Hubbard, R. \& Hall, I. Toll-like receptor (TLR) 4 polymorphisms and COPD. Thorax 59, 81 (2004).

126. Sarir, H., Henricks, P.A., van Houwelingen, A.H., Nijkamp, F.P. \& Folkerts, G. Cells, mediators and Toll-like receptors in COPD. Eur. J. Pharmacol. 585, 346-353 (2008).

127. Droemann, D., Goldmann, T., Tiedje, T., Zabel, P., Dalhoff, K. \& Schaaf, B. Toll-like receptor 2 expression is decreased on alveolar macrophages in cigarette smokers and COPD patients. Respir. Res. 6, 68 (2005).

128. Pabst, S. et al. Toll-like receptor 2 gene polymorphisms Arg677Trp and Arg753Gln in chronic obstructive pulmonary disease. Lung 187, 173-178 (2009).

129. Doz, E. et al. Cigarette smoke-induced pulmonary inflammation is TLR4/ MyD88 and IL-1R1/MyD88 signaling dependent. J. Immunol. 180, 1169-1178 (2008).
130. Sarir, H. et al. Cigarette smoke regulates the expression of TLR4 and IL-8 production by human macrophages. J. Inflamm. (Lond) 6, 12 (2009).

131. Szebeni, B. et al. Increased expression of Toll-like receptor (TLR) 2 and TLR4 in the colonic mucosa of children with inflammatory bowel disease. Clin. Exp. Immunol. 151, 34-41 (2008).

132. Canto, E. et al. TNF alpha production to TLR2 ligands in active IBD patients. Clin. Immunol. 119, 156-165 (2006).

133. Hong, J., Leung, E., Fraser, A.G., Merriman, T.R., Vishnu, P. \& Krissansen, G.W. TLR2, TLR4 and TLR9 polymorphisms and Crohn's disease in a New Zealand Caucasian cohort. J. Gastroenterol. Hepatol. 22, 1760-1766 (2007).

134. Rigoli, L. et al. Clinical significance of NOD2/CARD15 and Toll-like receptor 4 gene single nucleotide polymorphisms in inflammatory bowel disease. World J. Gastroenterol. 14, 4454-4461 (2008).

135. Shen, X., Shi, R., Zhang, H., Li, K., Zhao, Y. \& Zhang, R. The Toll-like receptor 4 D299G and T399I polymorphisms are associated with Crohn's disease and ulcerative colitis: a meta-analysis. Digestion $\mathbf{8 1}$, 69-77 (2010).

136. Speletas, M. et al. Association of TLR4-T399I polymorphism with chronic obstructive pulmonary disease in smokers. Clin. Dev. Immunol. 2009, 260286 (2009).

137. Abreu, M.T., Vora, P., Faure, E., Thomas, L.S., Arnold, E.T. \& Arditi, M. Decreased expression of Toll-like receptor- 4 and MD-2 correlates with intestinal epithelial cell protection against dysregulated proinflammatory gene expression in response to bacterial lipopolysaccharide. J. Immunol. 167, 1609-1616 (2001).

138. Suzuki, M., Hisamatsu, T. \& Podolsky, D.K. Gamma interferon augments the intracellular pathway for lipopolysaccharide (LPS) recognition in human intestinal epithelial cells through coordinated up-regulation of LPS uptake and expression of the intracellular Toll-like receptor 4-MD-2 complex. Infect. Immunol. 71, 3503-3511 (2003).

139. Vlahos, R. et al. Differential protease, innate immunity, and NF-kappaB induction profiles during lung inflammation induced by subchronic cigarette smoke exposure in mice. Am. J. Physiol. Lung Cell Mol. Physiol. 290, L931-L945 (2006).

140. Lee, S.H. et al. Antielastin autoimmunity in tobacco smoking-induced emphysema. Nat. Med. 13, 567-569 (2007).

141. Churg, A., Wang, R., Wang, X., Onnervik, P.O., Thim, K. \& Wright, J.L. Effect of an MMP-9/MMP-12 inhibitor on smoke-induced emphysema and airway remodelling in guinea pigs. Thorax 62, 706-713 (2007).

142. Vernooy, J.H., Lindeman, J.H., Jacobs, J.A., Hanemaaijer, R. \& Wouters, E.F. Increased activity of matrix metalloproteinase-8 and matrix metalloproteinase-9 in induced sputum from patients with COPD. Chest 126, 1802-1810 (2004).

143. Ohkawara, T. et al. Amelioration of dextran sulfate sodium-induced colitis by anti-macrophage migration inhibitory factor antibody in mice. Gastroenterology 123, 256-270 (2002).

144. Garg, P., Vijay-Kumar, M., Wang, L., Gewirtz, A.T., Merlin, D. \& Sitaraman, S.V. Matrix metalloproteinase-9-mediated tissue injury overrides the protective effect of matrix metalloproteinase-2 during colitis. Am. J. Physiol. Gastrointest. Liver Physiol. 296, G175-G184 (2009).

145. Medina, C. et al. Matrix metalloproteinase- 9 modulates intestinal injury in rats with transmural colitis. J. Leukoc. Biol. 79, 954-962 (2006).

146. Pender, S.L., Li, C.K., Di Sabatino, A., MacDonald, T.T. \& Buckley, M.G. Role of macrophage metalloelastase in gut inflammation. Ann. NY Acad. Sci. 1072, 386-388 (2006).

147. Yang, P. et al. Alpha1-antitrypsin and neutrophil elastase imbalance and lung cancer risk. Chest 128, 445-452 (2005).

148. Churg, A., Wang, X., Wang, R.D., Meixner, S.C., Pryzdial, E.L. \& Wright, J.L. Alpha1-antitrypsin suppresses TNF-alpha and MMP-12 production by cigarette smoke-stimulated macrophages. Am. J. Respir Cell Mol. Biol. 37, 144-151 (2007).

149. Sandford, A.J., Weir, T.D., Spinelli, J.J. \& Pare, P.D. Z and S mutations of the alpha1-antitrypsin gene and the risk of chronic obstructive pulmonary disease. Am. J. Respir. Cell Mol. Biol. 20, 287-291 (1999).

150. Sandford, A.J., Weir, T.D. \& Pare, P.D. Genetic risk factors for chronic obstructive pulmonary disease. Eur. Respir J. 10, 1380-1391 (1997).

151. Biancone, L., Fantini, M., Tosti, C., Bozzi, R., Vavassori, P. \& Pallone, F. Fecal alpha 1-antitrypsin clearance as a marker of clinical relapse in patients with Crohn's disease of the distal ileum. Eur. J. Gastroenterol. Hepatol. 15, 261-266 (2003). 
152. Meyers, S., Wolke, A., Field, S.P., Feuer, E.J., Johnson, J.W. \& Janowitz, H.D. Fecal alpha 1-antitrypsin measurement: an indicator of Crohn's disease activity. Gastroenterology 89, 13-18 (1985).

153. Elzouki, A.N., Eriksson, S., Lofberg, R., Nassberger, L., Wieslander, J. \& Lindgren, S. The prevalence and clinical significance of alpha 1antitrypsin deficiency (PiZ) and ANCA specificities (proteinase 3, BPI) in patients with ulcerative colitis. Inflamm. Bowel Dis. 5, 246-252 (1999).

154. Yang, P., Tremaine, W.J., Meyer, R.L. \& Prakash, U.B. Alpha1-antitrypsin deficiency and inflammatory bowel diseases. Mayo Clin. Proc. 75, 450-455 (2000).

155. Sinden, N.J. \& Stockley, R.A. Systemic inflammation and comorbidity in COPD: a result of 'overspill' of inflammatory mediators from the lungs? Thorax 65, 930-936 (2010).

156. Eagan, T.M.L. et al. Body composition and plasma levels of inflammatory biomarkers in COPD. Eur. Respir. J. 36, 1027-1033 (2010).

157. Barnes, P.J. \& Celli, B.R. Systemic manifestations and comorbidities of COPD. Eur. Respir. J. 33, 1165-1185 (2009).

158. Danese, S. et al. Extraintestinal manifestations in inflammatory bowel disease. World J. Gastroenterol. 11, 7227-7236 (2005).

159. Rothfuss, K.S., Stange, E.F. \& Herrlinger, K.R. Extraintestinal manifestations and complications in inflammatory bowel diseases. World J. Gastroenterol. 12, 4819-4831 (2006).

160. Butcher, E.C. \& Picker, L.J. Lymphocyte homing and homeostasis. Science 272, 60-66 (1996).

161. Hart, A.L., Ng, S.C., Mann, E., Al-Hassi, H.O., Bernardo, D. \& Knight, S.C. Homing of immune cells: role in homeostasis and intestinal inflammation. Inflamm. Bowel Dis. 16, 1969-1977 (2010).

162. Sauleda, J., Garcia-Palmer, F.J., Gonzalez, G., Palou, A. \& Agusti, A.G. The activity of cytochrome oxidase is increased in circulating lymphocytes of patients with chronic obstructive pulmonary disease, asthma, and chronic arthritis. Am. J. Respir Crit. Care Med. 161, 32-35 (2000).

163. Salmi, M., Granfors, K., MacDermott, R. \& Jalkanen, S. Aberrant binding of lamina propria lymphocytes to vascular endothelium in inflammatory bowel diseases. Gastroenterology 106, 596-605 (1994).

164. Salmi, M., Andrew, D.P., Butcher, E.C. \& Jalkanen, S. Dual binding capacity of mucosal immunoblasts to mucosal and synovial endothelium in humans: dissection of the molecular mechanisms. J. Exp. Med. 181, 137-149 (1995).

165. Eksteen, B. et al. Hepatic endothelial CCL25 mediates the recruitment of CCR9+ gut-homing lymphocytes to the liver in primary sclerosing cholangitis. J Exp. Med. 200, 1511-1517 (2004).

166. Bonniere, P. et al. Latent pulmonary involvement in Crohn's disease: biological, functional, bronchoalveolar lavage and scintigraphic studies. Gut 27, 919-925 (1986).

167. Wallaert, B. et al. Evidence of lymphocyte alveolitis in Crohn's disease. Chest 87, 363-367 (1985).

168. Fireman, Z. et al. The use of induced sputum in the assessment of pulmonary involvement in Crohn's disease. Am. J. Gastroenterol. 95, 730-734 (2000).

169. Hodge, G., Mukaro, V., Reynolds, P.N. \& Hodge, S. Role of increased CD8/CD28(null) T cells and alternative co-stimulatory molecules in chronic obstructive pulmonary disease. Clin. Exp. Immunol. 166, 94-102 (2011).

170. Brozyna, S. et al. Chemotactic mediators of Th1 T-cell trafficking in smokers and COPD patients. COPD 6, 4-16 (2009).

171. Lommatzsch, M. et al. Acute effects of tobacco smoke on human airway dendritic cells in vivo. Eur. Respir. J. 35, 1130-1136 (2010).

172. Bratke, K. et al. Function-associated surface molecules on airway dendritic cells in cigarette smokers. Am. J. Respir. Cell Mol. Biol. 38, 655-660 (2008).

173. Tsoumakidou, M. et al. Cigarette smoking alters bronchial mucosal immunity in asthma. Am. J. Respir. Crit. Care Med. 175, 919-925 (2007).

174. Robbins, C.S. et al. Cigarette smoke decreases pulmonary dendritic cells and impacts antiviral immune responsiveness. Am. J. Respir Cell Mol. Biol. 30, 202-211 (2004).

175. Verschuere, S. et al. Cigarette smoking alters epithelial apoptosis and immune composition in murine GALT. Lab. Invest. 91, 1056-1067 (2011).

176. Fujimura, Y., Kamoi, R. \& lida, M. Pathogenesis of aphthoid ulcers in Crohn's disease: correlative findings by magnifying colonoscopy, electron microscopy, and immunohistochemistry. Gut 38, 724-732 (1996).

177. Plevy, S.E. et al. A role for TNF-alpha and mucosal Thelper-1 cytokines in the pathogenesis of Crohn's disease. J. Immunol. 159, 6276-6282 (1997).

178. van Deventer, S.J. Transmembrane TNF-alpha, induction of apoptosis, and the efficacy of TNF-targeting therapies in Crohn's disease. Gastroenterology 121, 1242-1246 (2001).

179. Doubremelle, M. et al. Treatment of Crohn's disease with anti-TNF alpha antibodies (infliximab): results of a multicentric and retrospective study]. Gastroenterol. Clin. Biol. 26, 973-979 (2002).

180. Antoniu, S.A. Infliximab for chronic obstructive pulmonary disease: towards a more specific inflammation targeting? Expert. Opin. Investig. Drugs 15, 181-184 (2006).

181. Pizarro, T.T., Arseneau, K.O. \& Cominelli, F. Lessons from genetically engineered animal models XI. Novel mouse models to study pathogenic mechanisms of Crohn's disease. Am. J. Physiol. Gastrointest. Liver Physiol. 278, G665-G669 (2000).

182. Ruwanpura, S.M. et al. Interleukin-6 promotes pulmonary emphysema associated with apoptosis in mice. Am. J. Respir. Cell Mol. Biol. 45, 720-730 (2011).

183. Xiong, Z., Leme, A.S., Ray, P., Shapiro, S.D. \& Lee, J.S. CX3CR1+ lung mononuclear phagocytes spatially confined to the interstitium produce TNF-alpha and IL-6 and promote cigarette smoke-induced emphysema. J. Immunol. 186, 3206-3214 (2011).

184. Danese, S. \& Gao, B. Interleukin-6: a therapeutic Jekyll and Hyde in gastrointestinal and hepatic diseases. Gut 59, 149-151 (2010).

185. Eastaff-Leung, N., Mabarrack, N., Barbour, A., Cummins, A. \& Barry, S. Foxp3+ regulatory T cells, Th17 effector cells, and cytokine environment in inflammatory bowel disease. J. Clin. Immunol. 30, 80-89 (2010).

186. Vargas-Rojas, M.I., Ramirez-Venegas, A., Limon-Camacho, L., Ochoa, L., Hernandez-Zenteno, R. \& Sansores, R.H. Increase of Th17 cells in peripheral blood of patients with chronic obstructive pulmonary disease. Respir. Med. 105, 1648-1654 (2011).

187. Kimura, A. \& Kishimoto, T. IL-6: regulator of Treg/Th17 balance. Eur. J. Immunol. 40, 1830-1835 (2010).

188. Hansbro, P.M., Kaiko, G.E. \& Foster, P.S. Cytokine/anti-cytokine therapynovel treatments for asthma? Br. J. Pharmacol. 163, 81-95 (2011).

189. Horvat, J.C. et al. Chlamydial respiratory infection during allergen sensitization drives neutrophilic allergic airways disease. J. Immunol. 184, 4159-4169 (2010).

190. Essilfie, A-T. et al. Haemophilus influenzae infection drives IL-17mediated neutrophilic allergic airways disease. PLOS Pathog. 7, e1002244 (2011).

191. Olsen, T., Rismo, R., Cui, G., Goll, R., Christiansen, I. \& Florholmen, J. $\mathrm{TH} 1$ and TH17 interactions in untreated inflamed mucosa of inflammatory bowel disease, and their potential to mediate the inflammation. Cytokine; advance online publication 25 September 2011; doi:10.1016/ j.cyto.2011.08.036.

192. Leon, A.J. et al. High levels of proinflammatory cytokines, but not markers of tissue injury, in unaffected intestinal areas from patients with IBD. Mediators Inflamm. 2009, 580450 (2009).

193. Kim, E.Y. et al. Persistent activation of an innate immune response translates respiratory viral infection into chronic lung disease. Nat. Med. 14, 633-640 (2008).

194. Liu, S.F. et al. Il13 promoter (-1055) polymorphisms associated with chronic obstructive pulmonary disease in Taiwanese. Exp. Lung. Res. 35, 807-816 (2009).

195. Asquith, K.L. et al. Interleukin-13 promotes susceptibility to chlamydial infection of the respiratory and genital tracts. PLoS Pathog. 7, e1001339 (2011).

196. Kaiko, G.E. et al. Chlamydia muridarum infection subverts dendritic cell function to promote Th2 immunity and airways hyperreactivity. J. Immunol. 180, 2225-2232 (2008).

197. Hansbro, N.G., Horvat, J.C., Wark, P.A. \& Hansbro, P.M. Understanding the mechanisms of viral induced asthma: new therapeutic directions. Pharmacol. Ther. 117, 313-353 (2008).

198. Nofziger, C. et al. STAT6 links IL-4/IL-13 stimulation with pendrin expression in asthma and chronic obstructive pulmonary disease. Clin. Pharmacol. Ther. 90, 399-405 (2011).

199. Fuss, I.J. et al. Nonclassical CD1d-restricted NK T cells that produce IL-13 characterize an atypical Th2 response in ulcerative colitis. J. Clin. Invest. 113, 1490-1497 (2004). 
200. Fuss, I.J. \& Strober, W. The role of IL-13 and NK T cells in experimental and human ulcerative colitis. Mucosal. Immunol. 1 (Suppl 1), S31-S33 (2008).

201. Rosen, M.J. et al. STAT6 activation in ulcerative colitis: a new target for prevention of IL-13-induced colon epithelial cell dysfunction. Inflamm. Bowel Dis. 17, 2224-2234 (2011).

202. King, T.E. Jr, Savici, D. \& Campbell, P.A. Phagocytosis and killing of Listeria monocytogenes by alveolar macrophages: smokers versus nonsmokers. J. Infect. Dis. 158, 1309-1316 (1988).

203. Lode, H. et al. A prediction model for bacterial etiology in acute exacerbations of COPD. Infection 35, 143-149 (2007).

204. Soler, N. et al. Bronchial microbial patterns in severe exacerbations of chronic obstructive pulmonary disease (COPD) requiring mechanical ventilation. Am. J. Respir Crit. Care Med. 157 (5 Part 1), 1498-1505 (1998).

205. Ertel, A., Eng, R. \& Smith, S.M. The differential effect of cigarette smoke on the growth of bacteria found in humans. Chest 100, 628-630 (1991).

206. Kau, A.L., Ahern, P.P., Griffin, N.W., Goodman, A.L. \& Gordon, J.I. Human nutrition, the gut microbiome and the immune system. Nature 474, 327-336 (2011).

207. Ehlers, S. \& Kaufmann, S.H. Infection, inflammation, and chronic diseases: consequences of a modern lifestyle. Trends Immuno/ 31, 184-190 (2010).

208. Borody, T.J., Warren, E.F., Leis, S.M., Surace, R., Ashman, O. \& Siarakas, S. Bacteriotherapy using fecal flora: toying with human motions. J. Clin. Gastroenterol. 38, 475-483 (2004).
209. Grehan, M.J., Borody, T.J., Leis, S.M., Campbell, J., Mitchell, H. \& Wettstein, A. Durable alteration of the colonic microbiota by the administration of donor fecal flora. J. Clin. Gastroenterol. 44, 551-561 (2010).

210. Zoetandal, E.G., Akkermans, A.D.L., Akkermans-van Vliet, W.M., de Visser, J.A. \& de Vos, W.M. The host genotype affects the bacterial community in the human gastrointestinal tract. Microb. Ecol. Health Dis. 13, 129-134 (2001).

211. Turnbaugh, P.J. et al. A core gut microbiome in obese and lean twins. Nature 457, 480-484 (2009).

212. Agusti, A., MacNee, W., Donaldson, K. \& Cosio, M. Hypothesis: does COPD have an autoimmune component? Thorax 58, 832-834 (2003).

213. Low, T.B., Greene, C.M., O'Neill, S.J. \& McElvaney, N.G. Quantification and evaluation of the role of antielastin autoantibodies in the emphysematous lung. Pulm. Med. 2011, 826160 (2011).

214. Shapiro, S.D. Proteinases in chronic obstructive pulmonary disease. Biochem. Soc. Trans. 30, 98-102 (2002).

215. Tzortzaki, E.G. \& Siafakas, N.M. A hypothesis for the initiation of COPD. Eur. Respir. J. 34, 310-315 (2009).

216. Das, K.M. \& Bajpai, M. Tropomyosins in human diseases: ulcerative colitis. Adv. Exp. Med. Biol. 644, 158-167 (2008).

217. Kraft, S.C., Bregman, E. \& Kirsner, J.B. Criteria for evaluating autoimmune phenomena in ulcerative colitis. Gastroenterology 43, 330-336 (1962).

218. Mirza, Z.K., Sastri, B., Lin, J.J-.C., Amenta, P.S. \& Das, K.M. Autoimmunity against human tropomyosin isoforms in ulcerative colitis: localization of specific human tropomyosin isoforms in the intestine and extraintestinal organs. Inflamm. Bowel Dis. 12, 1036-1043 (2006). 